DOI: $10.20287 /$ doc.d22.ac1

\title{
A queima: vozes e ruídos na construção de um mito
}

\author{
Ester Maria Silva Rosendo*
}

\author{
A queima (Brasil, 2013, 13 min.) \\ Direção: Diego Benevides \\ Roteiro: Diego Benevides e Gian Orsini \\ Produção: Pablo Maia \\ Produção Executiva: Diego Benevides e Carol Leal \\ Som: Gian Orsini \\ Direção de Fotografia: Luis Barbosa \\ Edição: Marcelo Coutinho \\ Elenco: Seu Tião, Dona Bola, Gilson Veríssimo, Jéssica Marcolino
}

A queima (2013) é um filme paraibano sobre mitos, imaginário coletivo e tradições orais que permeiam as regiões canavieiras nordestinas. É um documentário encenado sobre a construção de uma lenda, Macário, onde os personagens interpretam a si mesmos e improvisam histórias, uma mentira que se sustenta até o fim.

Observaremos as escolhas estéticas desse curta-metragem, a articulação entre som e imagem, e como o som assume papel central na narrativa.

Começa o filme. Ouvimos um som agudo constante, semelhante a um vento, que atravessa os créditos, assim como uma sequência de quatro planos estáticos, começando com um plano detalhe e terminando com um geral, que juntos apresentam um engenho ao fim de tarde, cheio de ferrugem e extremamente deteriorado (Fig. 1).

\footnotetext{
* Bacharel em Comunicação em Mídias Digitais. Universidade Federal da Paraíba, Departamento de Mídias Digitais, Grupo de Estudos em Cinema e Audiovisual - GECINE. 58.051-900, João Pessoa, Brasil. E-mail: esterrosendo@gmail.com
} 

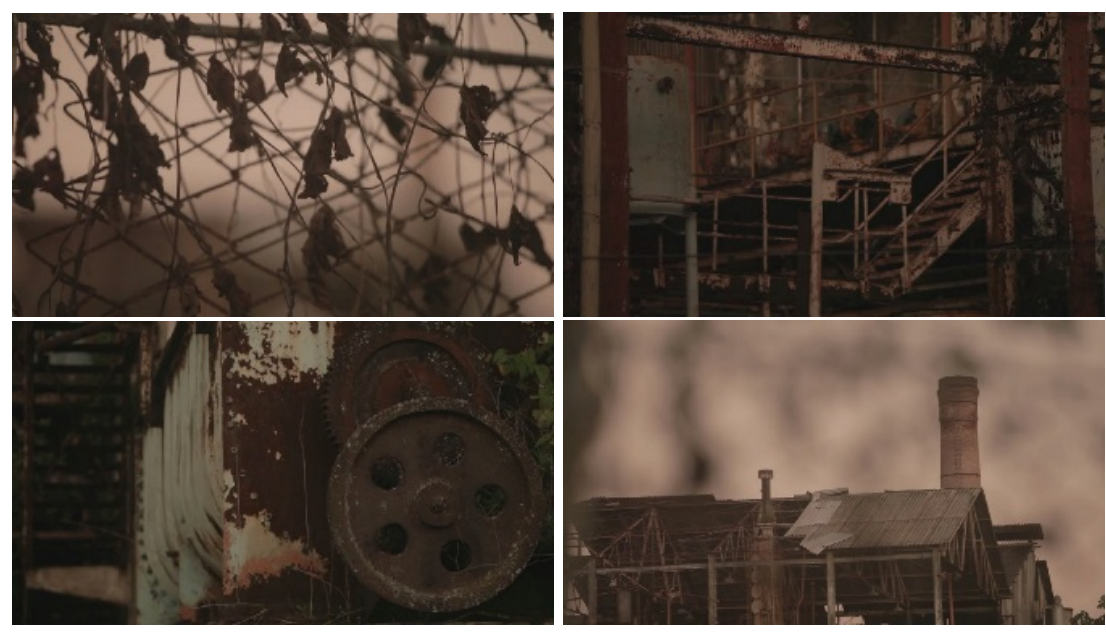

Figura 1

Fonte: print feito pela autora. Respectivamente: planos 1, 2, 3 e 4.

Ao longo desse primeiro minuto de filme também escutamos, em intensidade bem menor, um som pontual de um pássaro. Tem se tornado recorrente no cinema contemporâneo iniciar um filme com som antecedendo as imagens, essa escolha pode criar expectativa a respeito da fonte do som, confirmando ou confundindo o espectador.

A continuidade sonora da primeira cena gera uma unidade entre os planos, um espaço comum, deixando o espectador imerso na condução das imagens, à medida que distrai das mudanças visuais e o espaço. Se tirarmos o som da cena vemos, com exceção da primeira imagem em que há movimento das folhas dentro do quadro, imagens paradas, suspensas no tempo, semelhante à fotografias. O som aqui também age nas imagens lhes dando ritmo, movimento.

Ainda nesse trecho podemos perceber a configuração da paisagem sonora, terminologia desenvolvida por Murray Schafer (1997). Esse mesmo fenômeno é conceituado por Michel Chion, em seu livro A audiovisão (1990) como som ambiente: "Chamaremos som ambiente ao som de ambiência global que envolve uma cena e que habita o seu espaço [...]. Podemos chamar-lhes também sons território, que servem para marcar um lugar, um espaço particular com a sua presença contínua" (1990: 64). Sonoridades naturais, como vento, aves e insetos (cigarras e grilos) se tornam recorrentes. O controle da intensidade e ritmo dessa paisagem sonora, por vezes será o fator de tensão em algumas cenas do filme, como veremos mais à frente. 
O filme segue com um corte seco de som e imagem. Sons de cigarras surgem para ocupar a paisagem sonora, acompanhados de passos. A imagem apresenta em primeiro plano a silhueta de um rapaz (Gilson) andando ao fim do dia, em uma estrada entre canaviais, olhando sucessivamente para os lados. O plano-sequência é breve e cria uma expectativa acerca daquele indivíduo e suas motivações ao desviar o olhar seguidas vezes.

$\mathrm{Na}$ cena seguinte, ainda sob o pôr do sol, visualizamos em câmera fixa uma casa. Acende-se um lampião que ilumina um senhor (Seu Tião) que o está segurando, ele sai da casa, para diante da câmera e fala (Fig. 2).

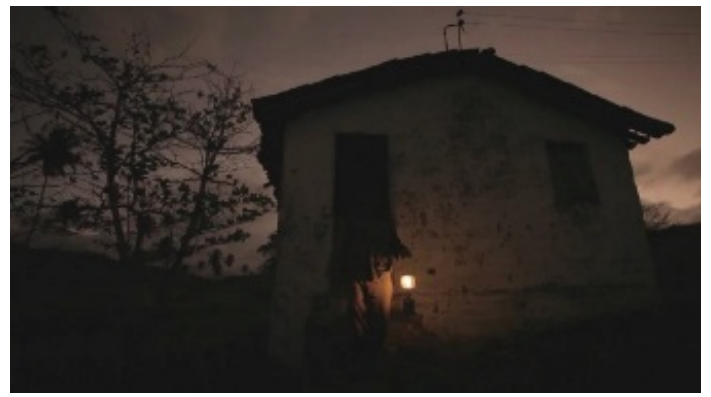

Figura 2

Fonte: print feito pela autora. Plano 6.

Ouvimos o som ambiente que caracteriza o espaço, zona rural, ao mesmo tempo em que o amplia, para além das margens do quadro. Utilizaremos a divisão dos espaços na tela conceituada por Chion, enquanto sons in (dentro de campo), fora de campo e off (fora da diegese).

Nesse plano ouvimos uma diversidade de camadas sonoras fora do campo que compõem o som ambiente de uma zona rural: Cigarras, grilos, pássaros. Assim como a fala de Seu Tião, enquanto som in, dentro do espaço onde vemos a fonte sonora.

Começamos a escutar um som manipulado, um elemento distinto nessa paisagem naturalista, uma frequência aguda constante e uns "assovios".

A mudança de perspectiva acontece quando o diálogo nos revela pela primeira vez o "Macário", entidade central dessa história, que atrapalha a vida dos cortadores de cana ao tentar impedir a queima do canavial, apagando o fogo, dando a entender ser o vento que não deixa a queima acontecer. Curiosamente, esses sons remetem ao primeiro som apresentado nos créditos iniciais do filme. Eles são intensificados à medida que o diálogo progride. Essas referências sonoras a partir de então serão entendidas em nosso texto como a 
representação do "Macário", sendo portando os ruídos, fora do campo, determinantes na construção narrativa do suspense empregado no filme.

O desenvolvimento da Acusmática (Schaeffer, 1966) no cinema vem sendo aplicado como modelador do suspense na narrativa. O seu efeito é de evocar elementos sonoros que não estão no campo, fazendo com que o espectador intua o que ele não consegue ver. Conectar essa experiência à narrativa do filme é uma das maneiras mais utilizadas para nos envolver e sustentar o clima de suspense.

A Acusmática tem uma forte presença na construção de suspense em $A$ queima. Não nos é mostrada a fonte de várias sonoridades que escutamos, como os assovios, o que acaba despertando nossa curiosidade e temor, desconhecemos a forma que emite o som, embora ela esteja presente, e nós, vulneráveis diante dela.

Podemos considerar as camadas sonoras que remetem ao "Macário" como um leitmotiv, pois elas retornam ao longo do filme e estão associadas a um personagem.

Voltamos a um momento de contemplação do canavial e da submersão sonora no ambiente, com pássaros e grilos a cantar.

Esse padrão, que se torna recorrente no curta, alterna-se com cenas de ritmo sonoro mais acelerado, com ataques bruscos, encadeadas de outra cena sonoramente mais amena, e vice-versa. Essa construção é parte fundamental de uma narrativa sonora do suspense.

Nesse contexto, somos postos, olhos e ouvidos, dentro da mata. Em um plano-sequência fechado, câmera na mão, um plongée (que mais esconde do que mostra) segue um homem dentro do canavial. O único ponto de luz sai de uma lanterna, a câmera perambula e desfoca, causando um ruído visual. O que nos orienta são os ruídos (sonoros) e a fala (Fig. 3).

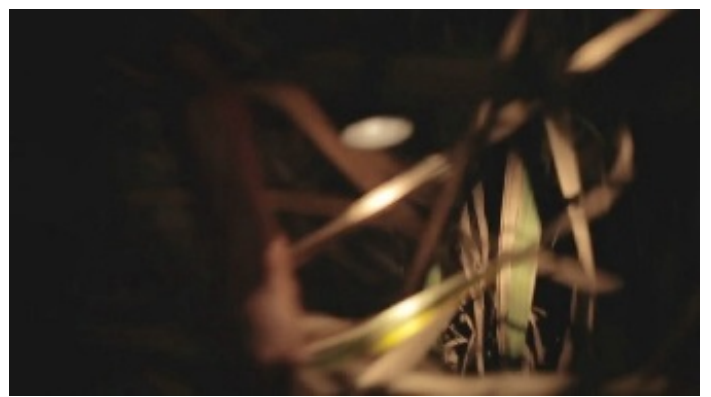

Figura 3

Fonte: print feito pela autora. Plano 12. 
Com fortes ataques e intensidade alta, sons do corpo do homem adentrando o canavial, pegando cana, seus passos, cigarras, grilos, morcegos (agudos pontuados), e, em último plano sonoro (com amplitude consideravelmente menor que os outros sons) um ruído constante semelhante a veículos transitando em estrada próxima. Tudo está em movimento: a câmera, as imagens, o compasso do personagem, e há uma correspondência mútua dos ritmos visuais e sonoros, juntos, comprimem, aceleram o tempo da diegese, e acentuam a sensação de perigo iminente.

A fala também contribui para potencializar o clima de tensão, ao citar a suposta entidade, Macário. O personagem conta que estava com amigos e acenderam um cigarro, em seguida começaram a ouvir o "assovio", e "rapidinho o cigarro foi embora", depois disso Macário foi embora, e eles ficaram aterrorizados, o homem também diz que existem outras histórias como essa nas redondezas.

Outra cena se utiliza dos mesmos recursos estéticos visuais e sonoros. Vemos em primeiro plano uma moça (Jéssica) que também entra no canavial, ela corta a cana e continua andando. Aqui ao invés da lanterna, uma lamparina ilumina parcialmente a imagem. A paisagem sonora nos rodeia com grilos e cigarras que já compunham a cena anterior, com uma intensidade maior e ritmo mais acelerado.

À medida que o plano-sequência segue, o assovio reaparece, e se torna cada vez mais presente, construindo em conjunto com os outros sons ambientes do canavial e passos cada vez mais apressados da moça (que olha incessantemente para os lados), uma densidade sonora que vai se fundindo à imagem fugidia. A cena termina com a moça saindo do canavial com a cana.

Nas duas cenas descritas, o som e a imagem geram uma expectativa em relação ao que pode acontecer aos personagens que estão imersos no canavial, e o clímax é sustentado por essa expectativa. Essa expectativa, por sua vez, não é alimentada, pois não acontecem reviravoltas na ação.

Embora não haja música no documentário, devemos considerar o caráter musical dos ruídos orquestrados que nos rodeiam, seus ritmos, modulações e dinâmicas, uma verdadeira orquestra de terror do canavial.

A voz no filme ressoa em diferentes espaços. Dentro da diegese, como nas cenas com os três personagens, apresentadas acima, e todas as outras em que eles aparecem no decorrer do filme, que analisaremos a seguir. E fora da diegese, em forma de voz-off, recurso que é adotado na fala de outra personagem, Dona Bôla. 
As diversas vozes de A queima norteiam a trama, elas seguem um mesmo fio condutor e tecem comentários que, entrelaçados, nos conduzem a montar uma imagem de Macário, e constroem um discurso que ganha verossimilhança.

As vozes também evocam a presença da entidade na história, e dão, junto aos ruídos, o tom de suspense. Em paralelo, mantêm viva a tradição oral.

Chion (2008) fala dos níveis de escuta: semântica, causal e reduzida. A escuta semântica se refere ao sentido (decodificado por nós) do que é dito, narrado. A causal é a mais utilizada, é quando somos informados pelo som qual é a sua causa, o que causou o som, podendo ser visto ou não na imagem, por exemplo, há vínculo causal entre voz e corpo. E por último, mas não menos importante, a escuta reduzida. Ela aprecia, valoriza o caráter sensorial, expressivo, rítmico, musical da voz.

Podemos perceber em A queima, que a expressividade da voz tem lugar de destaque e, muitas vezes, se sobrepõe à inteligibilidade do que é dito. O sotaque acentuado, a pronúncia de palavras não compreensíveis, são ferramentas que passam informações sobre aquelas pessoas, de onde são, nível de alfabetização, condição social, etc.

"O elemento sonoro mais proeminente no cinema narrativo clássico, como se sabe é a voz humana [...] o trabalho de mixagem quase sempre eleva os níveis de intensidade da voz acima dos demais componentes da trilha sonora (música e ruído)" (Carreiro, 2015). No caso de A queima esse princípio é parcialmente contrariado, o elemento sonoro mais recorrente é o ruído, mas quando a voz aparece ela ganha destaque e fica em primeiro plano sonoro.

Outra cena que faz uso da voz, dentro da diegese, se passa quando Jéssica volta para casa, depois de sair do canavial. Ela inicia com um plano médio que corta a cabeça da mulher e foca nela partindo a cana que pegou, há um movimento de câmera (na mão) e o foco agora passa para o fogo da lamparina.

Corta e o próximo plano se passa na área externa da casa, em primeiro plano, que acompanha Jéssica andando ao redor da casa e vai pra lamparina. Sons de cigarras chegam para compor a paisagem sonora. Jéssica nos revela que a cana é para jogar em volta da casa, em oferenda, para se livrar "deles".

Há outro corte, Jéssica dá a volta, ela olha incessantemente para os lados, para trás e a câmera faz um movimento semelhante, circundando a personagem, a imagem é escura e cheia de sombras. Ela nos conta que Gilson está para chegar do trabalho, ele foi fazer a queima da cana. Ouvimos um som pontual de latido de cachorro, que é reforçado por Jéssica que faz uma observação a respeito e apressa os passos, voltando para casa. Há mais um corte e a vemos entrando em casa, ouve-se o latido mais intenso e constante, a câmera acompanha Jéssica de cima a baixo, foca e desfoca, ela atravessa a casa e chega 
a uma janela aberta, olha fora, ouve-se o ruído de uma moto passar, ela fecha a janela.

Há uma tensão crescente apoiada no desenho sonoro e no ritmo visual, os sons de cigarra constantes quando Jéssica sai de casa, somados aos sons pontuais (latidos e moto), seus passos que ouvimos cada vez mais apressados e o sentido do que é dito, reafirmam o temor de Jéssica à presença de Macário. Percebemos aí que os indícios da sua presença foram entregues pelo trabalho do som, movimento de câmera e da personagem.

A narração em voz-off é um recurso onde a voz é acusmatizada, e fica em primeiro plano sonoro, sem ressonância. No filme temos quatro cenas em que ela é usada, a maioria por Dona Bôla.

Na primeira cena onde a voz-off se faz ouvir, vemos em câmera fixa o quadro emoldurado por paredes, onde aparece em profundidade de campo e foco parte da mesa e, em um plano mais afastado, a porta que dá para fora da casa, parcialmente aberta. Dona Bôla entra no nosso campo de visão, bota um café, vem em nossa direção, sai, volta ao campo, e por fim, vai embora pela porta, numa mise-en-scène que percorre diversos pontos do quadro e fora dele. Durante a ação escutamos uma voz-off, que imaginamos ser dela, ouvimos, através da escuta semântica, que ela já viu um bicho preto passando desconfiado por ali, o povo diz que não acredita, mas ela garante que existe. Na composição sonora também estão os sons mais naturalistas, diegéticos, que saem da personagem, dentro e fora de campo, seus passos, e sons do café no copo, além da paisagem sonora de fundo, com passarinhos e cigarras (Fig. 4).

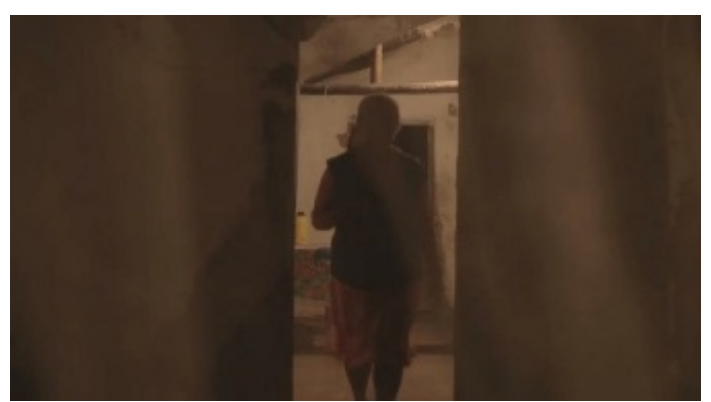

Figura 4

Fonte: print feito pela autora. Plano 19.

Outra cena que lança mão da voz-off se passa com Dona Bôla na frente de sua casa, em plano fixo vemos a silhueta dela emoldurada por sombras, sua boca não se mexe. 
Ela nos revela que não anda mais sozinha à noite, quando andava via mais coisas, também ouvimos cigarras, em intensidade bem menor do que a voz e constante. Dona Bôla sai do quadro, nos deixando em companhia do som ambiente.

A opção de prolongar a cena depois que a senhora vai embora, gera um contraste através do silêncio, que nos faz escutar e apreciar os ruídos naturais que ressoam no lugar, dando a eles um espaço. Faz ecoar na mente o que foi dito, amedrontando, e gerando uma espécie de pausa dramática. Essa situação de temor é acentuada por não vermos a personagem, quando ela sai do quadro. O ritmo do filme também é desacelerado pela imagem, praticamente sem movimento, em consonância com a paisagem sonora, constante e amena.

No caso da voz-off nessas cenas não vemos a fonte do som, mas imaginamos que a relação causal se dá com a senhora que vemos nas duas cenas, enquanto ouvimos sua voz em outro plano.

Nas duas cenas descritas o plano é fixo, e os únicos movimentos são realizados por Dona Bôla, a imagem não exige uma atenção maior, dada ao que é dito. Propiciando uma diminuição no ritmo do filme, pode-se sugerir aproximação com o indivíduo representado, que é captado pelas lentes, ele é o foco, e ele narra sua própria história. A aproximação também se deve ao fato da voz-off dar a impressão de aproximar os espaços do narrador e espectador, distanciando da ação.

Nesse aspecto o curta rompe, em algumas partes, e dialoga, em outras, com a estética do cinema narrativo clássico. Dialoga no momento em que deixa todas as vozes audíveis, em primeiro plano sonoro. E rompe (principalmente) quando opta por fazer uso das vozes-off de Dona Bôla, que estão no espaço fora da diegese, privilegiadas, mesmo quando a inteligibilidade está parcialmente comprometida pela pronuncia, reafirmando o interesse do filme em legitimar, além do sentido do que é contado, aqueles indivíduos.

Nesse contexto, Chion (2008) fala do discurso emanante, que se opõe ao vococentrismo. Ele pode não ser compreendido por inteiro e pode ser considerada uma emanação do próprio sujeito, seu contorno, caracterizando-o, expressando seu universo.

Como podemos perceber a voz tem papel estruturante na narrativa desse filme, se a tirarmos da história, as cenas ficam sem nexo, perdendo o valor que ela agrega, tanto informativo, quanto expressivo.

Corte seco, tela preta. Escutamos um som ambiente de fundo e som de manuseio de caixa de fósforo que logo é acendido. Aparece a imagem.

Alguém que só vemos o sapato está com fósforo na mão, entra no quadro e bota fogo em umas folhas de cana seca. No início da cena, ouvimos os sons 
da ação, mas não vemos a imagem. Essa falta de sincronização momentânea pode gerar uma expectativa em relação à fonte sonora, nos fazendo criar uma imagem que pode ou não ser confirmada no filme.

Entra a voz. Seu Tião diz que vai botar fogo na cana para ver se pega. O plano muda, vemos um plongée de Seu Tião olhando o fogo da cana seca queimar no canavial, logo ele sai do quadro, vemos e ouvimos a cana seca queimar lentamente.

No próximo plano, vemos Jéssica e Dona Bôla na porta de casa olhando para fora, iluminadas por uma luz vermelha, que pode ser o fogo descrito na cena anterior.

O som ambiente da cena anterior não continua e mantém só o som da queima em primeiro plano sonoro, através de uma ponte sonora, que liga as cenas, deixando ambíguo se elas também veem e ouvem a queima.

Acrescenta-se outro plano sonoro, ouvimos novamente a voz-off de Dona Bôla enquanto ela fecha a porta, a fala e o som da queima se estendem para próxima cena, outra ponte sonora, aonde as cigarras se somam (Fig. 5).
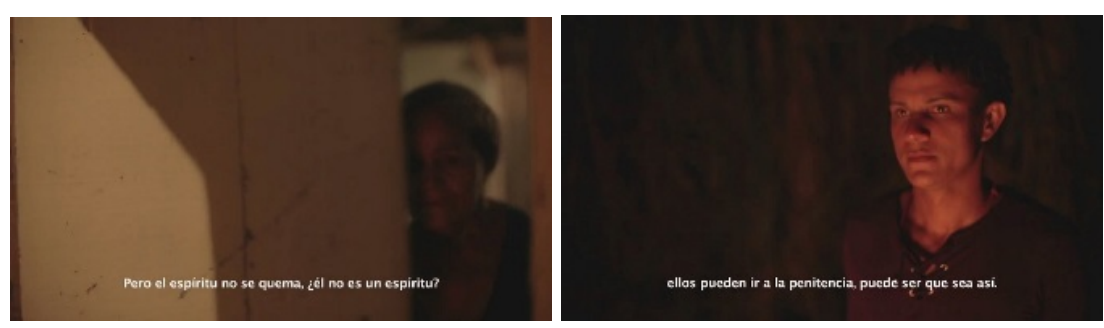

Figura 5

Fonte: print feito pela autora. Planos 43 e 44 .

Agora vemos Gilson (Fig. 5), também iluminado com luz vermelha, com a mata de fundo, ele sai do quadro, a voz prossegue, Dona Bôla nos conta que o Espírito não se queima, que depois da queima eles podem ir pra penitência, "o povo diz que é Macário".

Diferente das outras duas cenas com voz-off, todas de Dona Bôla, aqui a imagem não se fixa nela todo tempo, a voz perpassa e liga os planos das mulheres com o de Gilson, enquanto o ruído da queima une os últimos planos analisados, deixando ambíguo se os quatro personagens estavam compartilhando um lugar e tempo, e unificando o sentimento comum de esperança que eles têm de realizar a queima, sem que Macário apague o fogo.

O desenho de som constrói uma tensão crescente, pela permanência dos sons (voz que profetizam e evocam o espírito, e ruídos, que sugerem a presença 
da entidade) entre os planos, à medida que deixa de ser mais pontual e passa a ser mais constante.

O sentimento de esperança é reforçado com a próxima fala de Seu Tião, que diz o quanto o fogo é importante para eles, desde o cozimento dos alimentos, e que Macário só atrapalha, por ter raiva de fogo. Nesse momento a imagem sai de seu Tião (iluminado com luz avermelhada, que também tem a função de unificar os indivíduos e indicar uma possível partilha de tempo e espaço) e registra o que o fora de campo sonoro já nos dizia: o fogo se apagando no canavial. Ele completa dizendo que foi Macário, que é como um terror. A sugestão da presença de Macário também está no som ambiente dessa cena, semelhante ao vento agudo, que ouvimos no início do filme.

A próxima cena focaliza o preparo da comida, dentro de casa, com o fogão aceso, ouvimos o som da panela de pressão em primeiro plano sonoro, o próximo plano é um plano detalhe de um relógio, agora o único som em destaque é o do ponteiro do relógio, que marca 6 horas.

Nesses casos, explica Chion (2008: 72): "Poderíamos falar de extensão nula quando o universo sonoro se reduz aos ruídos ouvidos apenas por determinada personagem, e que não comporta nenhum outro [...]". Mas também são elementos do cenário sonoro que pontuam o quadro, criam sentidos e modulam o ritmo.

O foco visual e sonoro no relógio marca o tempo que está passando e eles não conseguiram fazer a queima da cana-de-açúcar. Também pode gerar uma espera por Seu Tião, único personagem do filme que não está presente, e pode estar correndo perigo no canavial.

Em um plano geral vemos Jéssica, Dona Bôla, Gilson e uma criança na mesa comendo, ainda vemos e ouvimos o relógio mas com intensidade bem menor, também se fazem ouvir os ruídos de talheres, acentuando o "silêncio" do momento, assim como relativiza a própria ideia de silêncio, que só é quebrado por Gilson que pergunta a Jéssica se ela lavou a roupa dele (Fig. 6). 


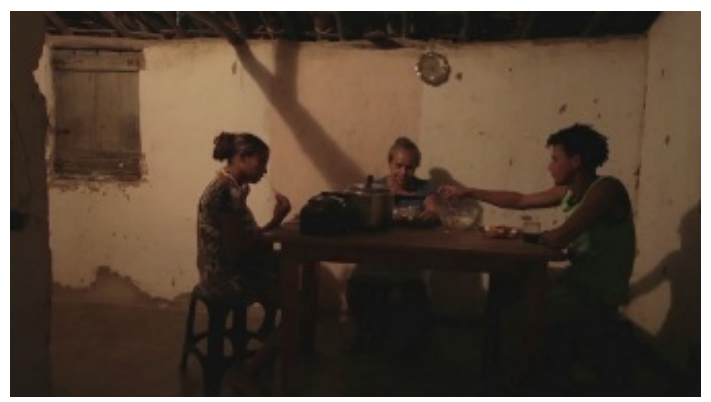

Figura 6

Fonte: print feito pela autora. Plano 50.

A voz-off de dona Bôla entra enquanto ela é focalizada pela imagem, ela nos conta que os mais velhos daquela região sabiam contar muitas histórias que aconteceram por lá, que viam mais coisas do que eles. O quadro muda enquanto as palavras continuam.

Entram cantos de passarinhos, vemos uma lamparina. Um som agudo, semelhante ao primeiro que escutamos no início do filme, com intensidade baixa, se sobrepõe em meio aos outros. Corta em sincronia com um som pontual de talher no prato, cortando audiovisualmente a cena, pontuando-a.

A senhora evoca a imagem do Macário através da sua fala, e começa uma sobreposição de sons que densificam a cena e remetem à Macário, ao mesmo tempo em que a lamparina aparece.

Tela escura, apenas o som agudo transita na ponte sonora entre cenas, depois de alguns segundos vemos um ponto de luz no meio do canavial, Seu Tião anda, segurando o lampião. A voz-off de Dona Bôla paira enquanto temos troca de planos, agora o lampião está em primeiro plano, uma sequência de 12 segundos. Ela diz que as entidades que permeiam aquele espaço estavam lá antes da cana. Voltamos ao plano do senhor adentrando a mata enquanto continuamos a ouvir o som agudo de baixa amplitude.

O som agudo, que entendemos enquanto representação de Macário, é o fio condutor que liga uma cena a outra e amplifica o suspense, à medida que é constante, suspende o tempo, gera expectativas. Ele nos conduz a uma tela preta, continuamos escutando brevemente. Com a permanência dos ruídos, através da ponte sonora ficamos na expectativa se o filme acabou ou não, logo em seguida ouvimos a voz (off) do senhor que acabara de sumir das nossas vistas. Começam os créditos finais. Seu Tião diz: "Macário, o espírito de Macário, que aconteceu hoje aqui, "mode" atrapalhar, "mode" mandar a chuva, "mode" a gente não queimar, fazer a queima, "mode" a gente não fazer o filme 
bem feito [entra assovio], mas acredito que ele amanhã não vem não, ele vai ter medo da gente e a gente vai ter mais força do que ele, o espírito de Macário, e a cana tá aqui ó [entra o ruído de cana amassada pontualmente], ele hoje pôde com a gente, mas amanhã ele não pode não, amanhã a gente quem pode com ele, e a gente dá a volta por cima". Terminam os créditos.

A fala novamente evoca a entidade, que aparece através do assovio. Evoca também, junto ao ruído, uma imagem mental da cana, e nos lembra que estamos vendo e ouvindo um filme, trazendo com isso uma série de reflexões que rompem com a pretensão de verdade, comumente associada ao fazer documentário (Nichols, 2007), e em paralelo, se mostra enquanto realidade construída.

Começa cena pós-crédito. Vemos, em primeiro plano, os braços do senhor segurando o lampião. O som se mantém (assovio e som agudo), vagueia, como um espírito, entre os planos. Entra a voz, ele diz que vai apagar o lampião para ficar mais fácil. Apaga o lampião, silêncio (Fig. 7).

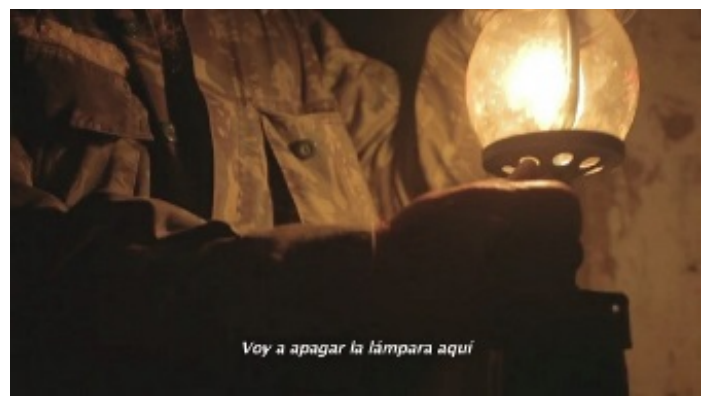

Figura 7

Fonte: print feito pela autora. Plano 59.

O filme mais uma vez rompe nossa expectativa, segue ao invés de terminar. O som e Macário insistem em ficar. A fala faz uma triangulação entre o apagar da luz do lampião, o fim do filme e o silêncio.

Há outra forma de interpretar simbolicamente as densidades sonoras, e o próprio Macário, dentro do contexto da narrativa. Os sons da natureza ressoam como um eco de resistência. Também podem representar simbolicamente a vida, na medida em que a queima representaria a morte da fauna e flora, que ali habitam, como insetos e pássaros que ouvimos, que parecem gritar "Aqui há vida”, ignorados pelos personagens que parecem só escutar e temer o espírito de Macário. Transparece também a resistência desses indivíduos, que continuam a ascender a luz, desejar o fogo e fazer a queima.

Por se tratar de um documentário, podemos ouvir a partir da construção sonora uma transgressão, no sentido mais enaltecedor da palavra, à forma clás- 
sica documental. Ao manipular os ruídos, a fim de transformá-los em elemento central na narrativa, ressignificando seu sentido, potencializando uma ideia, uma experiência, sugerindo, gerando expectativa, se apropriando de uma estética sonora de filmes de horror, e ao relativizar e expandir a própria ideia de documentário. O que torna o filme analisado ainda mais interessante quando falamos de experimentação estética e narrativa.

\section{Referências bibliográficas}

Carreiro, R. (2015). O uso do som em falsos documentários de horror. In G. Maia \& J. F. Serafim (org.), Ouvir o documentário: vozes, músicas, ruídos. Salvador; EDUFBA.

Chion, M. (2008). A audiovisão: som e imagem no cinema. Edições Texto \& Grafia.

Nichols, B. (2007). Introdução ao documentário. Campinas: Papirus Editora.

Schafer, M. (1997). A afinação do mundo. São Paulo: Editora UNESP.

Schaeffer, P. (1988). Tratado de los objetos musicales. Alianza Editorial.

\section{Filmografia}

A queima (2013), de Diego Benevides. 